\title{
Synthesis and Characterization of Dual-Ion- Crosslinked Magnetic Sodium Alginate-Based Fe- SA-Y@Fe304 Biogel Composite with Ultrastrong Performance for Azo Dye Removal
}

Beigang Li ( $\sim$ libeigang_1964@126.com )

Inner Mongolia Normal University https://orcid.org/0000-0002-8192-1877

Ting Lv

Inner Mongolia Normal University

Yanlong Shen

Inner Mongolia Normal University

\section{Research Article}

Keywords: Sodium alginate, Yttrium(III)-Iron(III) ions, Azo dyes adsorption, Magnetism, Biogel composite Posted Date: November 12th, 2021

DOI: https://doi.org/10.21203/rs.3.rs-1054926/v1

License: (c) (1) This work is licensed under a Creative Commons Attribution 4.0 International License. Read Full License

Version of Record: A version of this preprint was published at Journal of Polymers and the Environment on February 18th, 2022. See the published version at https://doi.org/10.1007/s10924-022-02404-6. 
Synthesis and characterization of dual-ion-crosslinked magnetic sodium alginate-based Fe-SA-Y@ $@ \mathrm{Fe}_{3} \mathrm{O}_{4}$ biogel composite with ultrastrong performance for azo dye removal

Beigang $L^{a, b, *}$, Ting $L v^{a, b}$, Yanlong Shen ${ }^{a, b}$

${ }^{a}$ Chemistry \& Environment Science College, Inner Mongolia Normal University, Hohhot 010022, China

${ }^{b}$ Inner Mongolia Key Laboratory of Environmental Chemistry, Hohhot 010022, China

${ }^{*}$ Corresponding author, Tel: +8613644715566

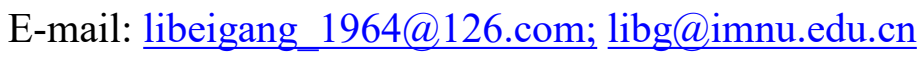

Journal of Polymers and the Environment 


\section{Abstract}

Magnetic sodium alginate(SA)-based biogel composite Fe-SA-Y@ $\mathrm{Fe}_{3} \mathrm{O}_{4}$ macroparticles were polymerized by co-crosslinking of yttrium(III) and iron(III) ions according to the optimized preparation conditions and characterized by various modern analytical techniques. The results show that the biogel beads have unique cauliflower-shaped surface and sensitive magnetic response. Fe-SA-Y@ $\mathrm{Fe}_{3} \mathrm{O}_{4}$ composite was used for the removal of Direct Red 13 (DR 13) and Direct Black 19 (DB 19) dyes from water. The adsorption capacities and removal efficiency can reach $2487 \mathrm{mg} / \mathrm{g}$ and $99.5 \%$ for DR-13 and $2992 \mathrm{mg} / \mathrm{g}$ and $99.7 \%$ for DB-19 respectively within the equilibrium time of $60 \mathrm{~min}$ at $298 \mathrm{~K}$ and $\mathrm{pH} 2.0$, and decrease slightly with $\mathrm{pH}$ up to 10.0 . The kinetic and equilibrium adsorption data followed the Pseudo-second-order rate model and Langmuir isothermal model well, respectively. Electrostatic adsorption, various H-bonding and complexation were largely involved in dye adsorption processes with spontaneous and exothermic character by the biogel beads, which were explained by thermodynamic studies, X-ray photoelectron spectroscopy (XPS) and Fourier transform infrared spectroscopy (FTIR), respectively. Fe-SA-Y@ $\mathrm{Fe}_{3} \mathrm{O}_{4}$ gel composite with ultrahigh adsorption capacity and fast magnetic separation will be a promising eco-friendly biobased adsorbent for the superefficient purification of practical azo-dye effluents.

Keywords: Sodium alginate $\cdot$ Yttrium(III)-Iron(III) ions · Azo dyes adsorption · Magnetism $\cdot$ Biogel composite 


\section{Introduction}

One of the main causes of environmental water pollution and harm to human health is the discharge of a large number of organic dyestuff wastewater produced in various industrial processes without treatment or incomplete pretreatment [1]. Familiar azo dyes are the most widely used synthetic dyes not only in textile, printing and dyeing processes, but also for coloring various paints, plastics, rubber and so on [2]. However, azo dyes in discharged effluents with high salinity and ecotoxicity [3] can be decomposed to produce more than 20 aromatic amines under special conditions, which may change the DNA structure of human body through activation and cause mutagenicity, teratogenicity and carcinogenicity [4,5]. Direct Red 13 (DR 13) and Direct Black 19 (DB 19), belonging to disazo and polyazo dyes, are often directly used for dyeing in producing industries of cellulose fibers, cotton, silk, leather, viscose and paper owing to their cheapness, good water solubility, color diversity, simplicity and directness of dyeing by H-bonding interaction and Van der Waals force [6]. Nevertheless, these dyes are difficult to discolor, weakly biodegradable and potentially toxic due to their complex aromatic ring structures. This has prompted the ceaseless research and development of various new physical or chemical water treatment technologies for effective removal of azo dyes from wastewater effluents, but among which, adsorption technology has been universally acknowledged as the most commonly used, the most economical, highly efficient, the fastest and easiest method to operate. Moreover, various types of adsorbents can be prepared due to the rich variety of raw materials, such as carbon-based/graphene-based composite adsorbents [7-11], metal-organic frameworks (MOFs)/nano adsorbents [5,12], 
adsorbents prepared from industrial and agricultural wastes and natural minerals/polymers [13-18] and so on. However, some powdered adsorbents are not easy to be thoroughly separated after wastewater treatment, resulting in partial loss and possible secondary pollution, and some adsorbents are difficult to be popularized in application due to high price and insufficient decontamination performance. Hence, developing low-cost, eco-friendly, high-capacity and swift-separation adsorbents have become the key to the efficient implementation of adsorption technology $[12,16]$.

Sodium alginate (SA), a natural polysaccharide polymer with rich marine sources, excellent biocompatibility and biodegradability, can be made into widely used hydrogels and has attracted extensive interest as a low-cost biomass material over recent years [19]. However, SA hydrogels have shortcomings of stability, mechanical strength and swelling properties, so SA has frequently been made into various gel composites as bio-based adsorbents to apply for the high-efficiency pollutants removal from industrial wastewater due to its strong hydrophilicity, good chemical reactivity, properties of spherical particles formed with suitable polyvalent metal ions and simplicity of preparation conditions and processes [20,21]. Recently, magnetic composites, as promising adsorbents, have been widely developed owing to their rapid separation and recovery from treated water by external magnetic field to solve the problem of incomplete separation of some powder adsorbents from water $[5,16,22]$.

Based on the previous research and above analysis [21], our study purpose was not only to make full use of the high polymerization activity of rare earth ions with SA, but also to reduce the preparation cost of adsorbent and improve the overall efficiency of adsorbent as much as possible. Therefore, a novel magnetic boigel copolymer (Fe-SA$\left.\mathrm{Y} @ \mathrm{Fe}_{3} \mathrm{O}_{4}\right)$ with biosafety was further prepared by a facile co-crosslinking 
polymerization of $\mathrm{Y}(\mathrm{III})$ and $\mathrm{Fe}(\mathrm{III})$ ions with $\mathrm{SA}$ and $\mathrm{Fe}_{3} \mathrm{O}_{4}$ to reduce the amount of rare earth Yttrium and dramatically improve the adsorption capacity, stability and mechanical properties of the gel composite, and reach the rapid separation from treated wastewater. Taking DR 13 and DB 19 dyes as adsorption objects, important preparation and adsorption conditions, adsorption dynamics and thermodynamics of Fe-SA$\mathrm{Y} @ \mathrm{Fe}_{3} \mathrm{O}_{4}$ gel composite for the target pollutants were investigated and its adsorption efficiency was evaluated. The dye-removed mechanism was explored. We hope to utilize natural biological resources to prepare cost-effective and eco-friendly macroparticle adsorbents with superlarge adsorption capacities and magnetic separation properties by a simple and feasible method, and realize the ultra-efficient purification of high-concentration azo dye wastewater.

\section{Material and methods}

\section{Chemicals and materials}

$\mathrm{FeCl}_{3} \cdot 6 \mathrm{H}_{2} \mathrm{O}(\mathrm{AR}), \mathrm{Y}\left(\mathrm{NO}_{3}\right)_{3} \cdot 6 \mathrm{H}_{2} \mathrm{O}(\mathrm{AR}), \mathrm{Fe}_{3} \mathrm{O}_{4}(\mathrm{AR})$ and sodium alginate (SA, AR) were purchased from Damao Chemical Reagent Factory (Tianjin, China). Direct Red 13 (DR 13, $\mathrm{C}_{32} \mathrm{H}_{22} \mathrm{~N}_{6} \mathrm{Na}_{2} \mathrm{O}_{7} \mathrm{~S}_{2}, \mathrm{M}_{\mathrm{r}}=712.66 \mathrm{~g} / \mathrm{mol}, \lambda_{\max }=510 \mathrm{~nm}$ ) and Direct Black 19 (DB 19, $\mathrm{C}_{34} \mathrm{H}_{27} \mathrm{~N}_{13} \mathrm{Na}_{2} \mathrm{O}_{7} \mathrm{~S}_{2}, \mathrm{M}_{\mathrm{r}}=839.77 \mathrm{~g} / \mathrm{mol}, \lambda$ max $=644 \mathrm{~nm}$ ) dyes were supplied by Jiaying Chemical Co., Ltd. (Shanghai, China), and dye molecular structures are shown in Fig. 1.

(Inserting Fig. 1 here)

\section{Synthesis of Fe-SA-Y@Fe $\mathrm{O}_{4}$ gel composite}

Fe-SA-Y@ $\mathrm{Fe}_{3} \mathrm{O}_{4}$ gel composite was synthesized by a facile droplet polymerization, and the specific preparation process was as follows: $0.1 \mathrm{~g} \mathrm{Fe}_{3} \mathrm{O}_{4}$ was added into $25 \mathrm{~mL} \mathrm{SA}$ solution of $16 \mathrm{~g} / \mathrm{L}$ with uniform stirring and ultrasonicated for $0.5 \mathrm{~h}$ at $25^{\circ} \mathrm{C}$, and then 
dripped evenly into the $30 \mathrm{~g} / \mathrm{L}$ mixed solution of Fe(III) and Y(III) ions with a mass ratio $\left(m_{\mathrm{Fe}}: m_{\mathrm{Y}}\right)$ of $2: 1$ by a syringe with $0.45 \mathrm{~mm}$ diameter. Black spherical beads were observed to produce continuously. After curing for $3 \mathrm{~h}$, the gel beads were removed, washed and dried, and magnetic bio-based adsorbent Fe-SA-Y@ $\mathrm{Fe}_{3} \mathrm{O}_{4}$ was obtained for further study.

\section{Characterization}

Scanning electronic microscopy and energy dispersive spectroscopy (SEM-EDS, SU8010, Hitachi Inc., Japan) were used to examine the micromorphology and elemental distribution of samples. Crystal structure of raw materials and the gel composite was analyzed by a X-ray diffractometer (XRD, PW-1830, Philips, Holland) using $\mathrm{Cu}-\mathrm{K} \alpha$ radiation source $(\lambda=0.154056 \mathrm{~nm})$. Fourier transform infrared (FTIR) spectra were measured by a FTIR spectrometer (KBr tabletting method, Nicolet 6700, Thermo Fisher Scientific, U.S.A). The magnetic property of the composite was determined on a vibrating sample magnetometer (VSM, 7407, Lake Shore Inc., USA). XPS analysis was performed on an x-ray photoelectron spectroscopy (XPS) with a monochromatized Al Ka X-ray source (Axis Ultra, Shimadzu Inc., Japan).

\section{Batch adsorption tests}

All adsorption experiments for DR 13 and DB 19 removal from aqueous solutions by Fe-SA-Y@ $\mathrm{Fe}_{3} \mathrm{O}_{4}$ gel composite were completed. Effects of initial dye concentration and solution $\mathrm{pH}$ on the dye adsorption were examined by adding $0.03 \mathrm{~g}$ dried gel beads into $25 \mathrm{~mL}$ dye solution with definite dye concentration and shaking for $60 \mathrm{~min}$ at $298 \mathrm{~K}$. Similarly, the kinetic experiments affected by time and temperature, isothermal adsorption were further finished by batch adsorption experiments. After adsorption, each supernatant was separated, and then the residual dye concentration was determined 
by UV-vis spectrophotometry at $\lambda_{\max }$ of each dye, respectively. The amount $\left(Q_{\mathrm{t}}\right.$ and $Q_{\mathrm{e}}$, $\mathrm{mg} / \mathrm{g})$ and removal efficiency $(R, \%)$ of each dye adsorbed by the gel composite at contact time $t$ (min) and equilibrium were calculated by the following equations, respectively:

$$
\begin{aligned}
& Q_{\mathrm{t}}\left(\text { or } Q_{\mathrm{e}}\right)=\left(C_{0}-C_{\mathrm{e}}\right) \times V / W \\
& R=\left(C_{0}-C_{e}\right) / C_{0} \times 100 \%
\end{aligned}
$$

Where $C_{0}$ and $C_{\mathrm{e}}(\mathrm{mg} / \mathrm{L})$ are the dye concentrations before and after adsorption, respectively. $V(\mathrm{~L})$ and $W(\mathrm{~g})$ are the solution volume and adsorbent dosage, respectively.

The adsorption experiments of each sample were repeated at least three times and the determined mean value was used for result analysis, and the precision of each-group data was controlled within the relative standard deviation $(R S D)$ less than $2 \%$.

\section{Different models and formulas used in data analysis}

In order to clarify the adsorption rate and control its key step in the adsorption processes, to judge the adsorption performance of Fe-SA-Y@ $\mathrm{Fe}_{3} \mathrm{O}_{4}$ gel composite for azo dyes and study deeply the adsorption behavior and interaction mechanism, the used different models and equations were listed in Table 1.

(Inserting Table 1 here)

\section{Results and discussion}

\section{Optimization of preparation conditions for Fe-SA-Y@ $\mathrm{Fe}_{3} \mathrm{O}_{4}$ gel composite}

As a crosslinking agent of SA-based composites, the proportioning of Fe(III) and Y(III) double ions is a key factor to produce stable gel bead polymer. When the concentrations of SA solution and mixed solution of $\mathrm{Fe}(\mathrm{III})$ and Y(III) ions were fixed at 16 and $10 \mathrm{~g} / \mathrm{L}$ respectively, mixed solutions with different ion mass ratios $\left(m_{\mathrm{Fe}}: m_{\mathrm{Y}}\right)$ were used for the 
synthesis of Fe-SA-Y polymer at room temperature, and the obtained polymer was further applied to the adsorption of DR 13 and DB 19 dyes respectively. As shown in Fig. 2 ( $a$ and b), the adsorption amounts of DR 13 and DB 19 onto Fe-SA-Y polymers prepared by dual-ion polymerization were obviously higher than those onto Fe-SA and Y-SA polymer crosslinked by a single metal ion with SA. Moreover, the dye adsorption amounts and removal rates reached the maximum values with $1247 \mathrm{mg} / \mathrm{g}$ and $95.9 \%$ for DR 13 and $1371 \mathrm{mg} / \mathrm{g}$ and 97.9\% for DB 19 respectively when the dual-ion mass ratio $\left(m_{\mathrm{Fe}}: m_{\mathrm{Y}}\right)$ was $2: 1$, indicating that the Fe-SA-Y polymer prepared by dual-ion cocrosslinking SA has extremely significant improvement on the adsorption efficiency of azo dyes from the water. Hence, the mass ratio of $m_{\mathrm{Fe}}: m_{\mathrm{Y}}=2: 1$ was chosen to prepare Fe-SA-Y gel composite.

When the SA concentration and dual-ion mass ratio were $16 \mathrm{~g} / \mathrm{L}$ and $2: 1$, the adsorption performance of different Fe-SA-Y polymers synthesized by changing total ion concentration $\left(C_{\mathrm{Fe}+\mathrm{Y}}, \mathrm{g} / \mathrm{L}\right)$ for two dyes are presented in Fig. 2c. When the total ionmixed concentration increased from 5 to $30 \mathrm{~g} / \mathrm{L}$, the adsorption amounts $\left(Q_{\mathrm{e}}, \mathrm{mg} / \mathrm{g}\right)$ of DR 13 and DB 19 by Fe-SA-Y increased dramatically from 676 and $531 \mathrm{mg} / \mathrm{g}$ to 1694 and $1841 \mathrm{mg} / \mathrm{g}$ and the removal rates $(R, \%)$ also increased rapidly from 39.5 and $28.6 \%$ to 98.8 and $99.1 \%$, respectively, indicating that each dye was almost removed from water. After that, the $Q_{\mathrm{e}}(\mathrm{mg} / \mathrm{g})$ and $R(\%)$ values of DR 13 and DB 19 were unchanged nearly with keeping on increasing the ion-mixed concentration. Therefore, the $30 \mathrm{~g} / \mathrm{L}$ concentration of $\mathrm{Fe}(\mathrm{III})$ and $\mathrm{Y}(\mathrm{III})$ ion-mixed solution was selected for preparing FeSA-Y polymer.

(Inserting Fig. 2 here) 
In preparing process of $\mathrm{Fe}-\mathrm{SA}-\mathrm{Y}$ polymer, $\mathrm{Fe}_{3} \mathrm{O}_{4}$ was further added to obtain the magnetic Fe-SA-Y@ $\mathrm{Fe}_{3} \mathrm{O}_{4}$ composite, and effect of $\mathrm{Fe}_{3} \mathrm{O}_{4}$ concentration on adsorption properties of Fe-SA-Y@ $\mathrm{Fe}_{3} \mathrm{O}_{4}$ for azo dyes were explored. As shown in Fig. 2d, Fe-SA$\mathrm{Y} @ \mathrm{Fe}_{3} \mathrm{O}_{4}$ prepared by $4.0 \mathrm{~g} / \mathrm{L}$ of $\mathrm{Fe}_{3} \mathrm{O}_{4}$ solution had the best adsorption effect and good magnetic separation performance, and higher adsorption capability than Fe-SA-Y polymer for two dyes. The influence of curing time on the stability and integrity of formed gel composite after crosslinking polymerization was presented in Fig. 2e. The $Q_{\mathrm{e}}(\mathrm{mg} / \mathrm{g})$ and $R(\%)$ values of Fe-SA-Y $@ \mathrm{Fe}_{3} \mathrm{O}_{4}$ for DR 13 and DB 19 dyes went up rapidly with aging time from 2 to $3 \mathrm{~h}$, and then changed little with time extension. Consequently, $3 \mathrm{~h}$ of the curing time was selected by comprehensive consideration. In addition, the effect of crosslinking reaction temperature on $\mathrm{Fe}-\mathrm{SA}-\mathrm{Y} @ \mathrm{Fe}_{3} \mathrm{O}_{4}$ properties was also examined. As given in Fig. 2f, the adsorption efficiency of two dyes onto FeSA-Y@ $\mathrm{Fe}_{3} \mathrm{O}_{4}$ only appeared slight downward trend overall with a rise of crosslinking temperature from 25 to $55^{\circ} \mathrm{C}$, indicating that $25^{\circ} \mathrm{C}$ was most suitable for the preparation of gel composite, which was convenient and energy-saving for practical application.

\section{Material characterization}

As shown in the SEM micrographs of Fig. 3a and b, the dried black magnetic composite Fe-SA-Y@ $\mathrm{Fe}_{3} \mathrm{O}_{4}$ gel beads synthesized by milky-white powder SA exhibit a unique cauliflower-like surface with grooves and crevices of different depths and uneven shape, which is very favorable for reinforcing the adsorption properties of gel composite. Concurrently, some white particles were found to be dispersed on the surface of gel beads, which should be the solid $\mathrm{Fe}_{3} \mathrm{O}_{4}$. The same phenomena were also observed in the previous reports[27,28]. Furthermore, according to the EDS results of element distribution presented in Fig. 3c and d, the contents of Fe and Y undetected in SA were 
26.1 and $5.4 \%$ in Fe-SA-Y $@ \mathrm{Fe}_{3} \mathrm{O}_{4}$ respectively, and $11.0 \%$ of the $\mathrm{Na}$ content in SA reduced dramatically to $0.34 \%$ in the composite. The element distribution including $\mathrm{C}$, $\mathrm{O}, \mathrm{Fe}, \mathrm{Y}$ and $\mathrm{Na}$ in gel beads was also very uniform (Fig. $3 \mathrm{e} \sim \mathrm{j}$ ) and a small part of Feelement aggregation was observed (Fig. 3k), which was consistent with the white spots in SEM images. These results fully indicated that ion exchange reaction between Fe(III) and Y(III) ions and $\mathrm{Na}^{+}$ions in SA solution first occurred, and then the magnetic gel beads with so-called "egg-box" structure were successfully synthetized by crosslinking polymerization of dual ions with SA molecular chains [29].

\section{(Inserting Fig. 3 here)}

In the XRD patterns of Fig. 31. three diffraction peaks $\left(2 \theta: 13.7^{\circ}, 21.7^{\circ}\right.$ and $\left.37.8^{\circ}\right)$ on the SA curve $[11,21]$ almost disappeared on the XRD pattern of Fe-SA-Y@ $\mathrm{Fe}_{3} \mathrm{O}_{4}$ [29], but the typical diffraction peaks at $2 \theta$ of $30.34^{\circ}, 35.64^{\circ}, 53.60^{\circ}, 57.34^{\circ}$ and $62.94^{\circ}$ appeared, which should belong to the characteristic peaks of $\mathrm{Fe}_{3} \mathrm{O}_{4}$ [20], confirming the successful synthesis of $\mathrm{Fe}-\mathrm{SA}-\mathrm{Y} @ \mathrm{Fe}_{3} \mathrm{O}_{4}$ composite. It was known from the magnetic hysteresis loop of Fig. $4 b$ that the saturation magnetization value of Fe-SA-Y@ $\mathrm{Fe}_{3} \mathrm{O}_{4}$ was $7.06 \mathrm{emu} / \mathrm{g}$. Meanwhile, the experimental test illustrated that a small permanent magnet was placed on a bottle wall, and dye-adsorbed gel beads in the bottle were instantly assembled onto the wall (Fig. 3m), proving that Fe-SA-Y@ $\mathrm{Fe}_{3} \mathrm{O}_{4}$ has the sensitive magnetic response property and can be quickly separated from treated water by a external magnetic field without secondary pollution and adsorbent loss.

\section{Effect of contact time and temperature and adsorption kinetics}

When adsorption technology is used for wastewater treatment, the adsorption-required equilibrium time and temperature directly determine the actual investment, application cost and treatment efficiency. The adsorption amounts $\left(Q_{\mathrm{t}}\right)$ of DR 13 and DB 19 onto 
Fe-SA-Y@ $\mathrm{Fe}_{3} \mathrm{O}_{4}$ at $298 \mathrm{~K}$ dramatically increased in 10 min of contact time, and then increased slowly with time increase in Fig. 4a. The adsorption equilibrium of each dye could be reached within $90 \mathrm{~min}$, and the corresponding $Q_{\mathrm{t}}$ value was up to 2416 and $2856 \mathrm{mg} / \mathrm{g}$ for DR 13 and DB 19, respectively. The adsorption rate of each dye concurrently descended with temperature increase from $298 \mathrm{~K}$ to $328 \mathrm{~K}$, but the temperature had no effect on the time required for reaching adsorption equilibrium. The results indicate that $\mathrm{Fe}-\mathrm{SA}-\mathrm{Y} @ \mathrm{Fe}_{3} \mathrm{O}_{4}$ gel composite with the fast adsorption equilibrium and ultrahigh adsorption amounts, as a very potential bio-based adsorbent, has the best decolorization effect on azo dye wastewater at room temperature.

(Inserting Fig. 4 near here)

To describe the dynamic processes of adsorption systems well and clarify the control step of adsorption rate, the pseudo-first-order and pseudo-second-order rate models and intraparticle diffusion model were respectively used to analyze kinetic data of each dye adsorption onto Fe-SA-Y@ $\mathrm{Fe}_{3} \mathrm{O}_{4}$ in the light of Eqs. (3) (5) in Table 1, and the goodness-of-fit of rate models to the experimental data was evaluated by calculating relative error $(R E, \%)=\left(Q_{\mathrm{e}, \exp }-Q_{\mathrm{e}, \text { calc }}\right) / Q_{\mathrm{e}, \exp } \times 100$ [30]. The fitting results in Table 2 elucidated that the kinetic data for each dye adsorption at different temperatures were completely consistent with the pseudo-second-order model (the correlation coefficient $\left.R^{2} \geq 0.999\right)$, and had more perfect goodness-of-fit $(R E:-6.9 \sim-0.78 \%)$ for the pseudosecond-order model than the pseudo-first-order model $\left(R^{2} \geq 0.745 ; R E: 90 \sim 69 \%\right)$. The calculated $Q_{\mathrm{e}, 2}$ values were very close to those of experimental $Q_{\mathrm{e}, \text { exp }}$, suggesting the occurrence of chemisorption [31]. Moreover, a reduction in pseudo-second-order rate constant $\left(k_{2}\right)$ with temperature increase indicated the exothermic adsorption. Similar phenomenon has also been reported [28].

(Inserting Table 2 here) 
The whole process of dye adsorption is usually divided into three steps: liquid film diffusion, pore diffusion and physicochemical adsorption onto adsorbent surface [32]. In this study, all kinetic experimental data were further processed using the intraparticle diffusion model (Eq. 5 in Table 1) for grasping a key step to control the adsorption rate [25]. According to the results in Fig. $4 \mathrm{~b}$ and Table 2, the initial fast stages and second slow stages in the adsorption process of each dye onto the gel beads were primarily controlled by the intraparticle diffusion (pore diffusion), but were not the only one.

\section{Effect of dye concentration and adsorption isotherms}

The influence of initial dye concentration on the adsorption capacities $\left(Q_{\mathrm{e}}\right)$ of the gel composite are given in Fig. 4c. When the initial concentration of DR 13 solution increased from 2000 to $3400 \mathrm{mg} / \mathrm{L}$, the $Q_{\mathrm{e}}(\mathrm{mg} / \mathrm{g})$ value increased from 1649 to 2354 $\mathrm{mg} / \mathrm{g}$ while $R(\%)$ value decreased slightly from 98.9 to $83.1 \%$. Similarly, the $Q_{\mathrm{e}}$ value of DB 19 increased from 1658 to $2742 \mathrm{mg} / \mathrm{g}$ while $R$ (\%) value only decreased a little from 99.5 to $91.4 \%$ with a rise in the initial concentration from 2000 to $3600 \mathrm{mg} / \mathrm{L}$. This is due to the rapid mass transfer of dye anions with high contents in the solution and the sufficient number of active sites on the adsorbent surface, but $R(\%)$ value reduced gradually with the saturation of active sites. Further studies showed that the $Q_{\mathrm{e}}$ value of each dye diminished with increasing in temperature from $298 \mathrm{~K}$ to $328 \mathrm{~K}$ in the absorption isotherms of Fig. 4d, which were in line with the impact results of temperature on dye adsorption kinetics. The isothermal data of each dye adsorption onto Fe-SA-Y@ $\mathrm{Fe}_{3} \mathrm{O}_{4}$ at different temperatures were respectively handled with Langmuir, Freundlich and Dubinin-Radushkevich (D-R) models (Eqs. 6 10 in Table 1), and the results are shown in Table 3. By comparing the correlation coefficient $\left(R^{2}\right)$ for fitting three models, the equilibrium data was most consistent with the Langmuir model $\left(R^{2} \geq\right.$ 
0.998) and the fitting result owned the more significant goodness-of-fit (root mean squared error: RMSE $\left.\leq 5.9 \times 10^{-3}\right)$ than the Freundlich model $\left(R^{2} \geq 0.849\right.$; RMSE $\leq$ $2.2 \times 10^{-2}$ ) at each temperature [33]. The maximum $Q_{\mathrm{m}}$ value of each dye was very near the actual equilibrium $Q_{\text {e,exp }}$ (Table 3 ), demonstrating the occurrence of monolayer adsorption. Hence, the Langmuir model can describe the dye adsorption behavior well. Some adsorption studies obtained similar results [8,21]. In general, the mean adsorption energy $(E)$ from D-R model with the range of $1 \sim 8 \mathrm{~kJ} / \mathrm{mol}$ and more than $8 \mathrm{~kJ} / \mathrm{mol}$ can predict the occurrence of physical adsorption and chemical adsorption, respectively [34]. The $E$ values of DR 13 and DB 19 adsorption, from 23.4 to $22.3 \mathrm{~kJ} / \mathrm{mol}$ and from 8.98 to $7.42 \mathrm{~kJ} / \mathrm{mol}$ at $298 \mathrm{~K} \sim 328 \mathrm{~K}$, respectively, revealed the mechanism involving the chemisorption and micropore filling. The Langmuir constant $\left(K_{\mathrm{L}}\right)$ and Freundlich constant $\left(K_{\mathrm{F}}\right)$ related to adsorption strength and affinity reduced with temperature increasing from $298 \mathrm{~K}$ to $328 \mathrm{~K}$, suggesting the exothermic nature of adsorption systems and confirming that the room temperature could better enhance the adsorption and be more convenient for practical application.

\section{(Inserting Table 3 here)}

The maximum adsorption capacities of different direct dyes onto various adsorbents previously reported are listed in Table 4. Quite evidently, as a eco-friendly bio-based adsorbent, Fe-SA-Y@ $\mathrm{Fe}_{3} \mathrm{O}_{4}$ gel beads with the magnetism has outperformed many other adsorbents and displayed very significant advantages with ultrastrong adsorption efficiency, rapid separation and recovery after treating water. In addition, the adsorption capacity of Fe-SA-Y@ $\mathrm{Fe}_{3} \mathrm{O}_{4}$ for DB 19 was larger than that for DR 13. This should be because there are more amino, azo and aromatic groups on the DB 19 molecules than 
those on DR 13 molecules (Fig. 1), resulting in more multisite interactions between the adsorbent and DB 19 molecules.

(Inserting Table 4 here)

\section{Adsorption thermodynamics}

According to Eqs. 11 and 12 in Table 1, three thermodynamic parameters, the change of Gibbs free energy $\left(\Delta G^{\circ}, \mathrm{kJ} / \mathrm{mol}\right)$, enthalpy change $\left(\Delta H^{\circ}, \mathrm{kJ} / \mathrm{mol}\right)$ and entropy change $\left(\Delta S^{\circ}, \mathrm{kJ} / \mathrm{mol} \cdot \mathrm{K}\right)$, were calculated to understand the feasibility and nature of adsorption reaction. The values of $\Delta H^{\circ}$ and $\Delta S^{\circ}$ obtained by the slope and intercept of the plot of $\ln K^{0}$ versus $1 / T\left(\right.$ DR $13: \ln K^{0}=2.4671 / T+0.00285, R^{2}=0.993 ;$ DB 19: $\ln K^{0}=4.1281 / T-$ $\left.0.00286, R^{2}=0.976\right)$ and $\Delta G^{\circ}$ values are listed in Table 3. The negative values of $\Delta G^{\circ}$ illustrated that the adsorption reactions were spontaneous and feasible. The negative values of $\Delta H^{\circ}$ with -20.5 kJ/mol (DR 13-Fe-SA-Y@ $\mathrm{Fe}_{3} \mathrm{O}_{4}$ ) and -34.3 kJ/mol (DB 19Fe-SA-Y@ $\left.\mathrm{Fe}_{3} \mathrm{O}_{4}\right)$ revealed the exothermic nature of dye adsorption. Some previous studies for azo dye adsorption also had similar results [21,31]. A small positive value of $\Delta S^{\circ}$ for DR 13 adsorption indicated the randomness increase at the solid-liquid interface due to the release of a large number of water molecules replaced by dye molecules, and also reconfirmed the good affinity of Fe-SA-Y@ $\mathrm{Fe}_{3} \mathrm{O}_{4}$ for DR 13 [22,40]. A negative $\Delta S^{\circ}$ value of $-0.0238 \mathrm{~kJ} /(\mathrm{mol} \cdot \mathrm{K})$ for $\mathrm{DB} 19$ adsorption indicated the increase of dyesorbed amount onto the composite and the enhancement of orderliness at the solidliquid interface due to the monolayer adsorption $[8,13]$.

\section{Effect of pH and adsorption mechanism}

Wastewater $\mathrm{pH}$ can directly affect the treatment efficiency of adsorbent application. Therefore, the effects of $\mathrm{pH}$ on the DR 13 and DB 19 adsorption onto Fe-SA-Y@ $\mathrm{Fe}_{3} \mathrm{O}_{4}$ were examined in detail. As presented in Fig. 4e, the $Q_{\mathrm{e}}$ values of DR 13 and DB 19 
adsorbed decreased only slightly from 2487 to $2334 \mathrm{mg} / \mathrm{g}$ and from 2992 to $2831 \mathrm{mg} / \mathrm{g}$ when the $\mathrm{pH}$ of dye solution increased from 2.0 to 10.0 , and the corresponding $R(\%)$ values reduced a little from 99.5 to $93.4 \%$ and from 99.7 to $94.4 \%$ respectively. After then the values of $Q_{\mathrm{e}}$ and $R$ reduced with $\mathrm{pH}$ increase from 10.0 to 12.0 . Meanwhile, the determined point of zero charge $\left(\mathrm{pH}_{\mathrm{pzc}}\right)$ of Fe-SA-Y@ $\mathrm{Fe}_{3} \mathrm{O}_{4}$ composite was 2.3 (Fig. 4f) [21], illustrating that the protonated positively charged surface of the gel composite promoted the adsorption of DR 13 and DB 19 anions by highly strong electrostatic attraction at $\mathrm{pH}<\mathrm{pH}_{\mathrm{pzc}}$ [8], leading to the maximum adsorption capacities with 2487 and $2992 \mathrm{mg} / \mathrm{g}$ for two dyes at $\mathrm{pH} 2.0$ [36]. When solution $\mathrm{pH}$ was greater than $\mathrm{pH}_{\mathrm{pzc}}$, the deprotonated negative charge density of the composite surface increased with $\mathrm{pH}$ increasing and should lead to a significant decrease of adsorption capacity owing to the increase of electrostatic repulsion force between the adsorbent and dye anions [7], but actual adsorption results were not so (Fig. 4e), suggesting that there were still other interacting mechanism. The abundant O-containing functional groups including $-\mathrm{COOH},-\mathrm{OH}, \mathrm{M}-\mathrm{OH}\left(\mathrm{M}: \mathrm{Fe}^{3+}\right.$ and $\left.\mathrm{Y}^{3+}\right)$ and $\mathrm{Fe}-\mathrm{O}\left(\mathrm{Fe}_{3} \mathrm{O}_{4}\right)$ on Fe-SA$\mathrm{Y} @ \mathrm{Fe}_{3} \mathrm{O}_{4}$ surface easily formed various multi-site $\mathrm{H}$-bonding interactions with - $\mathrm{NH}_{2}$, $\mathrm{OH},-\mathrm{N}=\mathrm{N}-,-\mathrm{SO}_{3}{ }^{-}$groups and -aromatic rings (Ar) on dye molecules, such as dipoledipole H-bonding $(\mathrm{O}-\mathrm{H} \cdots \mathrm{N}, \mathrm{O}-\mathrm{H} \cdots \mathrm{O}, \mathrm{O}-\mathrm{H} \cdots \mathrm{S}, \mathrm{M}-\mathrm{OH} \cdots \mathrm{N})[12,31,40]$, Yoshida Hbonding (-COOH $\cdots$ Ar, $-\mathrm{OH} \cdots \mathrm{Ar}, \mathrm{M}-\mathrm{OH} \cdots \mathrm{Ar})$ and $\mathrm{n}-\pi$ interaction $\left(-\mathrm{COO}^{-\cdots} \mathrm{Ar}, \mathrm{M}-\right.$ $\mathrm{O} \cdots \mathrm{Ar}$ ) at higher $\mathrm{pH}[16]$, which effectively improved the removal efficiency of dyes. Meanwhile, the complexation might be another important mechanism due to the deprotonation of Fe-SA-Y@ $\mathrm{Fe}_{3} \mathrm{O}_{4}$ polymer containing high-valence metals $\left(\mathrm{Y}^{3+}\right.$ and $\mathrm{Fe}^{3+}$ ) [29]. Concurrently, the unique cauliflower-like surface of gel beads with uneven three-dimensional structure was also very conducive to the rapid liquid film diffusion, 
pore migration and surface reaction of dye anions from the solution to the adsorbent inside. As a result, Fe-SA-Y@ $\mathrm{Fe}_{3} \mathrm{O}_{4}$ gel composite has exhibited the ultrahigh adsorption capacity and nearly $100 \%$ removal efficiency for two azo dyes in a wide $\mathrm{pH}$ range of 2.0-10.0. The homologous results of some direct dyes adsorption affected by $\mathrm{pH}$ have also been found [44]. The values of $Q_{\mathrm{e}}(\mathrm{mg} / \mathrm{g})$ and $R(\%)$ of the gel composite for DR 13 and DB 19 in each dye solution with a natural $\mathrm{pH}$ (8.0 and 9.0, respectively) could still achieve $2428 \mathrm{mg} / \mathrm{g}$ and $97.1 \%$, and $2844 \mathrm{mg} / \mathrm{g}$ and $95.0 \%$, respectively, so the gel composite can be directly applied to the superefficient treatment of dye wastewater without $\mathrm{pH}$ adjustment. This would be very favourable to reducing the cost of actual investment and simplifying the operation.

The FTIR spectra of Fe-SA-Y@ $\mathrm{Fe}_{3} \mathrm{O}_{4}$ composite before and after dye adsorption were measured as shown in Fig. 5a, the positions and intensities of characteristic peaks at around $3395(-\mathrm{OH}), 1626$ and 1383 (asymmetric and symmetric stretching vibration of $-\mathrm{COO}^{-}$, respectively), 1027 (C-O-C) and $565 \mathrm{~cm}^{-1}$ (Fe-O) on the composite FTIR spectrum [20] all moved and changed correspondingly after adsorbing DR 13 and DB 19 respectively, confirming that the O-containing active groups and $\mathrm{Fe}_{3} \mathrm{O}_{4}$ on the composite participated in the interaction with dye anions.

(Inserting Fig. 5 near here)

Furthermore, the XPS wide-scan spectra of Fe-SA-Y@ $\mathrm{Fe}_{3} \mathrm{O}_{4}$ before and after dye adsorption from Fig. 5b indicated that the gel composite mainly contained $\mathrm{C}, \mathrm{O}, \mathrm{Fe}$ and $\mathrm{Y}$ elements and the existence of $\mathrm{Fe} 2 \mathrm{p}$ peak derived from $\mathrm{Fe}_{3} \mathrm{O}_{4}$ confirmed successful magnetization of polymer [27]. Meanwhile, a new peak assigning to $\mathrm{N}$ 1s appeared on the XPS spectra of DR 13-loaded and DB 19-loaded Fe-SA-Y@ $\mathrm{Fe}_{3} \mathrm{O}_{4}$ respectively, illustrating that each dye was successfully bound to the gel composite. In the high- 
resolution XPS spectrum of C 1s (Fig. 5c), three peaks at binding energies of 284.7 $(\mathrm{C}-\mathrm{C}), 285.1(\mathrm{C}-\mathrm{O}, \mathrm{C}-\mathrm{OH})$ and $288.6 \mathrm{eV}\left(\mathrm{COO}^{-}\right)$[40] were shifted to 284.6, 285.5 and 287.6 eV after DR 13 adsorption, and 284.9, 286.1 and 288.8 eV after DB 19 adsorption, respectively, and all peak area ratios decreased. Two peaks with the binding energy of $532.3(\mathrm{C}-\mathrm{OH}, \mathrm{C}-\mathrm{O}-\mathrm{C})$ and $534.16 \mathrm{eV}\left(\mathrm{COO}^{-}, \mathrm{H}-\mathrm{O}-\mathrm{H}\right.$ : adsorbed water) $[7,14]$ on the O1s spectrum of the composite (Fig. 5d) were moved to 532.0 and $533.7 \mathrm{eV}$, and to 531.6 and $533.1 \mathrm{eV}$ after adsorbing DR 13 and DB 19, respectively. The corresponding area ratios changed into $1: 1.9$ and $1: 5.3$, and $1: 1.6$ and $1: 5.4$, respectively. In the highresolution XPS spectrum of $Y 3 d$ (Fig. 5e), two peaks assigned to $Y 3 d_{5 / 2}$ and $Y 3 d_{3 / 2}$ at 159.2 and $161.3 \mathrm{eV}$ demonstrated that the yttrium existed in the gel composite as Y(III) [48]. After adsorbing dyes, the binding energies of two peaks were slightly shifted to the low field direction with 159.0 and $161.0 \mathrm{eV}$ for DR 13-loaded composite and 158.7 and $160.6 \mathrm{eV}$ for DB 19-loaded composite, respectively, and corresponding area ratios decreased simultaneously, proposing that there was a complex reaction between Y(III) and dye anions. The spectra of $\mathrm{Fe} 2 \mathrm{p}_{3 / 2}$ and $\mathrm{Fe} 2 \mathrm{p}_{1 / 2}$ were respectively divided into four peaks at binding energies of 711.0, 713.1, 724.9 and $725.8 \mathrm{eV}$ on the high-resolution spectrum of Fe $2 p$ (Fig. 5f), proving the existence of $\mathrm{Fe}(\mathrm{III})$ with +3 oxidation state and $\mathrm{Fe}_{3} \mathrm{O}_{4}$ in the gel composite [49]. However, after adsorbing dyes, the position and intensity of each peak for Fe $2 \mathrm{p}$ changed accordingly. All XPS results indicated that the various O-containing active groups, synergistic effect of bimetallic ions with the unsaturated coordination [29] and $\mathrm{Fe}_{3} \mathrm{O}_{4}$ in $\mathrm{Fe}-\mathrm{SA}-\mathrm{Y} @ \mathrm{Fe}_{3} \mathrm{O}_{4}$ polymer were all involved in the hydrogen bonding and coordination reactions with the rich $-\mathrm{NH}_{2},-\mathrm{OH}$ and azo groups as well as aromatic rings in dye anions, which further verified the FTIR results. 
All results of material characterization, kinetic and thermodynamic studies and $\mathrm{pH}$ effect indicated that various interaction, mainly including electrostatic attraction, various H-bonding interaction and coordination reaction (Fig. 6), effectively promoted the strong multi-site adsorption of dyes by Fe-SA-Y@ $\mathrm{Fe}_{3} \mathrm{O}_{4}$ gel composite. Therefore, Fe-SA-Y@ $\mathrm{Fe}_{3} \mathrm{O}_{4}$ reveals ultra-high adsorption capacities for two azo dyes.

(Inserting Fig. 6 near here)

\section{Conclusions}

Magnetic gel composite Fe-SA-Y@ $\mathrm{Fe}_{3} \mathrm{O}_{4}$ synthesized by facile droplet polymerization using sodium alginate polymer as raw material exhibits outstanding adsorption performance, and has maximum adsorption capacities of 2487 and $2992 \mathrm{mg} / \mathrm{g}$ for DR 13 and DB 19 at 298K, respectively. The dye removal efficiency of almost $100 \%$ at $\mathrm{pH}$ 2.0 can still reach more than $94 \%$ with the increase of $\mathrm{pH}$ to 10.0 (Fig. 7). The Pseudosecond-order rate model and Langmuir model can accurately describe the spontaneous adsorption processes with exothermic properties and adsorption behavior, respectively. As an eco-friendly, separable and high value-added bio-based adsorbent, macroparticle Fe-SA-Y@ $\mathrm{Fe}_{3} \mathrm{O}_{4}$ gel composite would have considerable application potential for ultrastrong purification of azo-dye-containing effluents with various acidity.

\section{Acknowledgement}

This work was supported by the National Natural Science Foundation of China (21167011); the Natural Science Foundation of Inner Mongolia Autonomous Region, China (2020LH02009); and Collaborative Innovation Center for Water Environment Security of Inner Mongolia Autonomous Region, China (XTCX003). 


\section{Declarations of Competing Interest}

The authors declare that they have no known competing financial interests or personal relationships that could have appeared to influence the work reported in this paper.

\section{References}

1. Lellis B, Fávaro-Polonio CZ, Pamphile JA, Polonio JC (2019) Effects of textile dyes on health and the environment and bioremediation potential of living organisms. Biotechnol Res Innovat 3: 275-290. https://doi.org/10.1016/j.biori.2019.09. 001

2. Pavithra KG, Jaikumar V (2019) Removal of colorants from wastewater: a review on sources and treatment strategies. J Ind Eng Chem 75: 1-19. https://doi.org/ 10.1016/j.jiec.2019.02.011

3 Sivashankar R, Sathya AB, Krishnakumar Uma, Sivasubramanian V (2015) Synthesis of magnetic biocomposite for effificient adsorption of azo dye from aqueous solution. Ecotoxicol Environ Saf 121: 149-153. https://doi.org/10.1016/j. ecoenv. 2015.04.037

4 Brüschweiler BJ, Merlot C (2017) Azo dyes in clothing textiles can be cleaved into a series of mutagenic aromatic amines which are not regulated yet. Regul Toxicol Pharm 88: 214-226. https://doi.org/10.1016/j.yrtph.2017.06.012

5 Han L, Ge F, Sun G, Gao X, Zheng H (2019) Effective adsorption of Congo red by a MOF-based magnetic material. Dalton Trans 48: 4650-4656. https://doi.org/10. 1039/C9DT00813F

6 Adeel S, Usman M, Haider W, Saeed M, Muneer M, Ali M (2015) Dyeing of gamma irradiated cotton using direct yellow 12 and direct yellow 27: improvement in colour 
strength and fastness properties. Cellulose 22: 2095-2105. https://doi.org/10. 1007/s10570-015-0596-0

7 Liu N, Zhu M, Wang H, Ma H (2016) Adsorption characteristics of Direct Red 23 from aqueous solution by biochar. J Mol Liq 223: 335-342, https://doi.org/10. 1016/j.molliq.2016.08.061

8 Konicki W, Aleksandrzak M, Moszyński D, Mijowska E (2017) Adsorption of anionic azo-dyes from aqueous solutions onto graphene oxide: Equilibrium, kinetic and thermodynamic studies. J Colloid Interf Sci 496: 188-200. http://dx.doi. $\operatorname{org} / 10.1016 /$ j.jcis.2017.02.031

9 Karthick K, Namasivayam A, Pragasan LA (2017) Removal of Direct Red 12B from aqueous medium by $\mathrm{ZnCl}_{2}$ activated Jatropha husk carbon: Adsorption dynamics and equilibrium studies. Indian J Chem Techn 24: 73-81.

10 Azari A, Nabizadeh R, Nasseri S, Mahvi AH, Mesdaghinia AR (2020) Comprehensive systematic review and meta-analysis of dyes adsorption by carbonbased adsorbent materials: classification and analysis of last decade studies. Chemosphere 250: 126238. https://doi.org/10.1016/j.chemosphere.2020. 126238

11 Mohammadi A, Doctorsafaei AH, Zia KM (2018) Alginate/calix[4]arenes modified graphene oxide nanocomposite beads: preparation, characterization, and dye adsorption studies. Int J Biol Macromol 20: 1353-1361. https://doi.org/10. 1016/j.ijbiomac.2018.09.136

12 Chen J, Hu H, Yang J, Xue H, Tian Y, Fan K, Zeng Z, Yang J, Wang R, Liu Y (2021) Removal behaviors and mechanisms for series of azo dye wastewater by novel nano constructed macro-architectures material. Bioresour Technol 322: 124556. https://doi.org/10.1016/j.biortech.2020.124556 
13 Zheng L, Wang C, Shu Y, Yan X, Li L (2015) Utilization of diatomite/chitosan$\mathrm{Fe}(\mathrm{III})$ composite for the removal of anionic azo dyes from wastewater: Equilibrium, kinetics and thermodynamics. Colloids Surf A: Physicochem Eng Aspect 468: 129-139. https://doi.org/10.1016/j.colsurfa.2014.12.015

14 He X, Du M, Li H, Zhou T (2016) Removal of direct dyes from aqueous solution by oxidized starch cross-linked chitosan/silica hybrid membrane. Int J Biol Macromol 82: 174-181. https://doi.org/10.1016/j.ijbiomac.2015.11.005

15 Dhaif-Allah MAH, Syed AA (2018) Use of Kaolinite as an adsorbent: equilibrium and dynamics of adsorption of direct red 13 from aqueous solution. International Journal of Recent Scientific Research 9: 28260-28269. http://dx.doi.org/10. 24327/ijrsr.2018.0908.2427

16 Malek NNA, Jawad AH, Abdulhameed AS, Ismail K, Hameed BH (2020) New magnetic Schiff's base-chitosan-glyoxal/fly $\mathrm{ash} / \mathrm{Fe}_{3} \mathrm{O}_{4}$ biocomposite for the removal of anionic azo dye: An optimized process. Int J Biol Macromol 146: 530539. https://doi.org/10.1016/j.ijbiomac.2020.01.020

17 Li B, Chen C (2021) Novel magnetic gel composite based on sodium alginate crosslinked by Yttrium(III) as biosorbent for efficient removal of direct dyes from aqueous solution. J Disper Sci Techno. https://doi.org/10.1080/01932691.2021. 1924190

18 Bhatti HN, Safa Y, Yakout SM, Shair OH, Iqbal M, Nazir A (2020) Efficient removal of dyes using carboxymethyl cellulose/alginate/polyvinyl alcohol/rice husk composite: Adsorption/desorption, kinetics and recycling studies. Int J Biol Macromol 150: 861-870. https://doi.org/10.1016/j.ijbiomac.2020.02.093 
19 Ching SH, Bansal N, Bhandari B (2017) Alginate gel particles-a review of production techniques and physical properties. Crit Rev Food Sci Nutr 57: 11331152. https://doi.org/10.1080/10408398.2014.965773

20 Li X, Qi Y, Li Y, Zhang Y, He X, Wang Y (2013) Novel magnetic beads based on sodium alginate gel crosslinked by zirconium(IV) and their effective removal for $\mathrm{Pb}^{2+}$ in aqueous solutions by using a batch and continuous systems. Bioresour Technol 142: 611-619. https://doi.org/10.1016/j.biortech.2013.05.081

21 Li B, Yin H (2020) Superior adsorption property of a novel green biosorbent Yttrium/Alginate gel beads for dyes from aqueous solution. J Polym Environ 28: 2137-2148. https://doi.org/10.1007/s10924-020-01757-0

22 Saber-Samandari S, Yekta H, Mohseni M (2017) Adsorption of anionic and cationic dyes from aqueous solution using gelatin-based magnetic nanocomposite beads comprising carboxylic acid functionalized carbon nanotube. Chem Eng J 308: 1133-1144. https://doi.org/10.1016/j.cej.2016.10.017

23 Lagergren S (1898) About the theory of so-called adsorption of soluble substances. K Sven Vetenskapsakad Handl 24: 1-39. https://refhub.elsevier.com/S1226-086X (16)30137-X/sbref0190

24 Ho YS, McKay G (1999) Pseudo-second order model for sorption processes. Process Biochem 34: 451-465. https://doi.org/10.1016/S0032-9592(98)00112-5

25 Weber WJ, Morris JC (1963) Kinetics of adsorption on carbon from solution. J Sanit Eng Div Am Soc Civ Eng 89: 31. https://refhub.elsevier.com/S1226086X(16)30137-X/sbref0205

26 Milonjić SK (2007) A consideration of the correct calculation of thermodynamic parameters of adsorption. J Serb Chem Soc 72: 1363-1367. https://doi.org/10.2298/ 


\section{JSC0712363M}

27 Liang XX, Omer AM, Hu Z, Wang Y, Yu D, Ouyang X (2019) Effificient adsorption of diclofenac sodium from aqueous solutions using magnetic aminefunctionalized chitosan. Chemosphere 217: 270-278, https://doi.org/10.1016/j. chemosphere. 2018.11.023

28 Lv T, Li B (2021) Preparation of novel magnetic sodium alginate-ferric(III) gel beads and their super-efficient removal of direct dyes from water. J Polym Environ 29: 1576-1590. https://doi.org/10.1007/s10924-020-01977-4

29 Dong Y, Dong W, Cao Y, Han Z, Ding Z (2011) Preparation and catalytic activity of $\mathrm{Fe}$ alginate gel beads for oxidative degradation of azo dyes under visible light irradiation. Catalysis Today 175: 346-355. https://doi.org/10.1016/j.cattod.2011. 03.035

$30 \mathrm{Hu}$ J, Dai W, Yan X (2016) Comparison study on the adsorption performance of methylene blue and congo red on Cu-BTC. Desalin Water Treat 57: 4081-4089. https://doi.org/10.1080/19443994.2014.988654

31 Pan Y, Xie H, Liu H, Cai P, Xiao H (2019) Novel cellulose/montmorillonite mesoporous composite beads for dye removal in single and binary systems. Bioresour Technol 286: 121366. https://doi.org/10.1016/j.biortech.2019. 121366

32 Nethaji S, Sivasamy A (2011) Adsorptive removal of an acid dye by lignocellulosic waste biomass activated carbon: equilibrium and kinetic studies. Chemosphere. 82: 1367-1372. https://doi.org/10.1016/j.chemosphere.2010.11.080

33 Mokhtar A, Abdelkrim S, Djelad A, Sardi A, Boukoussa B, Sassi M, Bengueddach A (2020) Adsorption behavior of cationic and anionic dyes on magadiite-chitosan 
composite beads. Carbohyd Polym 229: 115399. https://doi.org/10.1016/j.carbpol. 2019.115399.

34 Chen A-H, Chen S-M (2009) Biosorption of azo dyes from aqueous solution by glutaraldehyde-crosslinked chitosans. J Hazard Mater 172: 1111-1121. https://doi.org/10.1016/j.jhazmat.2009.07.104.

35 Pellicer JA, Rodríguez-López MI, Fortea MI, Gabaldón Hernández J A, LucasAbellán C, Mercader-Ros MT, ‥ Ferrándiz M (2018) Removing of Direct Red 83:1 using $\alpha$ - and HP- $\alpha$-CDs polymerized with epichlorohydrin: Kinetic and equilibrium studies. Dyes and Pigments 149: 736-746. https://doi.org/10. 1016/j.dyepig.2017.11.032

36 Khan TA, Dahiya S, Ali I (2012) Removal of Direct Red 81 dye from aqueous solution by native and citric acid modified bamboo sawdust-kinetic study and equilibrium isotherm analyses. G U J Sci 25: 59-87.

37 Oladipo AA, Gazi M (2015) Microwaves initiated synthesis of activated carbonbased composite hydrogel for simultaneous removal of copper(II) ions and direct red 80 dye: A multi-component adsorption system. J Taiwan Inst Chem E 47: 125136. https://doi.org/10.1016/j.jtice.2014.09.027

38 Liu M, Xie Z, Ye H, Li W, Shi W, Liu Y, Zhang Y (2021) Waste polystyrene foamchitosan composite materials as high-efficient scavenger for the anionic dyes. Colloids Surf A: Physicochem Eng Aspect 627: 127155. https://doi.org/10. 1016/j.colsurfa.2021.127155

39 Dong X, Lin Y, Ma Y, Zhao L (2020) N-contaning UiO-67 derived multifunctional hybrid materials as highly effective adsorbents for removal of congo red. Inorg Chim Acta 510: 119748. https://doi.org/10.1016/j.ica.2020.119748 
40 Waheed A, Mansha M, Kazi IW, Ullah N (2019) Synthesis of a novel 3,5diacrylamidobenzoic acid based hyper-cross-linked resin for the efficient adsorption of Congo Red and Rhodamine B. J Hazard Mater 369: 528-538. https://doi.org/10.1016/j.jhazmat.2019.02.058

41 Ardejani FD, Badii KH, Limaee NY, Mahmoodi NM, Arami M, Shafaei SZ, Mirhabibi AR (2007) Numerical modelling and laboratory studies on the removal of Direct Red 23 and Direct Red 80 dyes from textile effluents using orange peel, a low-cost adsorbent. Dyes Pigm 73: 178-185. https://doi.org/10.1016/j.dyepig. 2005.11.011.

42 Achmad A, Kassim J, Suan TK, Amat RC, Seey TL (2012) Equilibrium, kinetic and thermodynamic studies on the adsorption of direct dye onto a novel green adsorbent developed from Uncaria Gambir extract. J Phys Sci 23: 1-13.

43 Liu N, Wang H, Weng C-H, Hwang C-C (2018) Adsorption characteristics of Direct Red 23 azo dye onto powdered tourmaline. Arabian J. Chem. 11: 1281-1291. http://dx.doi.org/10.1016/j.arabjc. 2016.04.010

44 Li B, Ren Z (2020) Superior adsorption of direct dye from aqueous solution by Y(III)-chitosan-doped fly ash composite as low-cost adsorbent. J Polym Environ 28: 1811-1821. https://doi.org/10.1007/s10924-020-01728-5

45 Safa Y, Bhatti HN (2011) Biosorption of Direct Red-31 and Direct Orange-26 dyes by rice husk: Application of factorial design analysis Chem Eng Res Des 89: 25662574. https://doi.org/10.1016/j.cherd.2011.06.003

46 Zohra B, Aicha K, Fatima S, Nourredine B, Zoubir D (2008) Adsorption of Direct Red 2 on bentonite modified by cetyltrimethylammonium bromide. Chem Eng J 136: 295-305. https://doi.org/10.1016/j.cej.2007.03.086 
47 Jin X, Chen Z, Zhou R, Chen Z (2015) Synthesis of kaolin supported nanoscale zero-valent iron and its degradation mechanism of Direct Fast Black $\mathrm{G}$ in aqueous solution. Mater Res Bull 61: 433-438. https://doi.org/10.1016/j.materresbull.2014. 10.057 .

48 Yu Y, Yu L, Sun M, Chen JP (2016) Facile synthesis of highly active hydrated yttrium oxide towards arsenate adsorption. J Colloid Interf Sci 474: 216-222. https://doi.org/10.1016/j.jcis.2016.03.030

49 Yamashita T, Hayes P (2008) Analysis of XPS spectra of $\mathrm{Fe}^{2+}$ and $\mathrm{Fe}^{3+}$ ions in oxide materials. Applied Surf Sci 254: 2441-2449. https://doi.org/10.1016/j.apsusc.2007. 09.063 . 
Figures

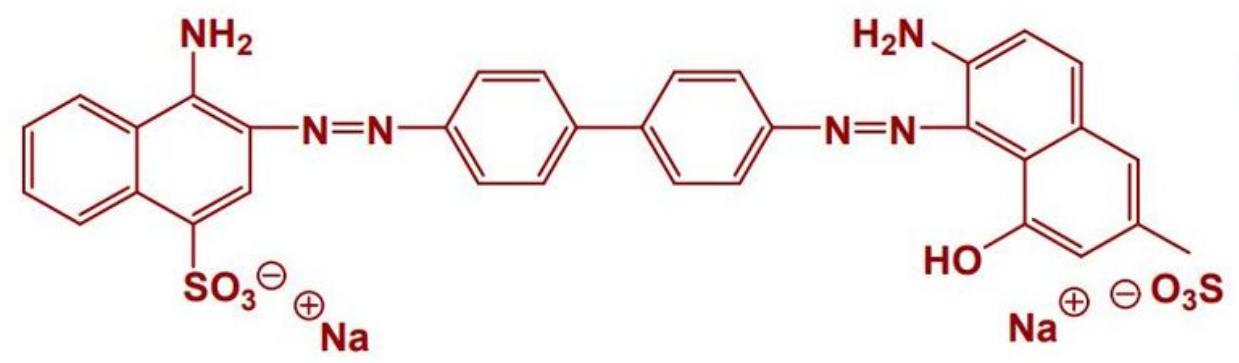

DR 13<smiles>Nc1ccc(N=Nc2ccc(N=Nc3c(S(=O)(=O)[O-])cc4cc([S+]([O])([O-])[O-])c(N=Nc5ccc(N=Nc6ccc(N)cc6N)cc5)c(O)c4c3N)cc2)c(N)c1</smiles>

\section{Figure 1}

Molecular structures of DR 13 and DB 19 dyes 

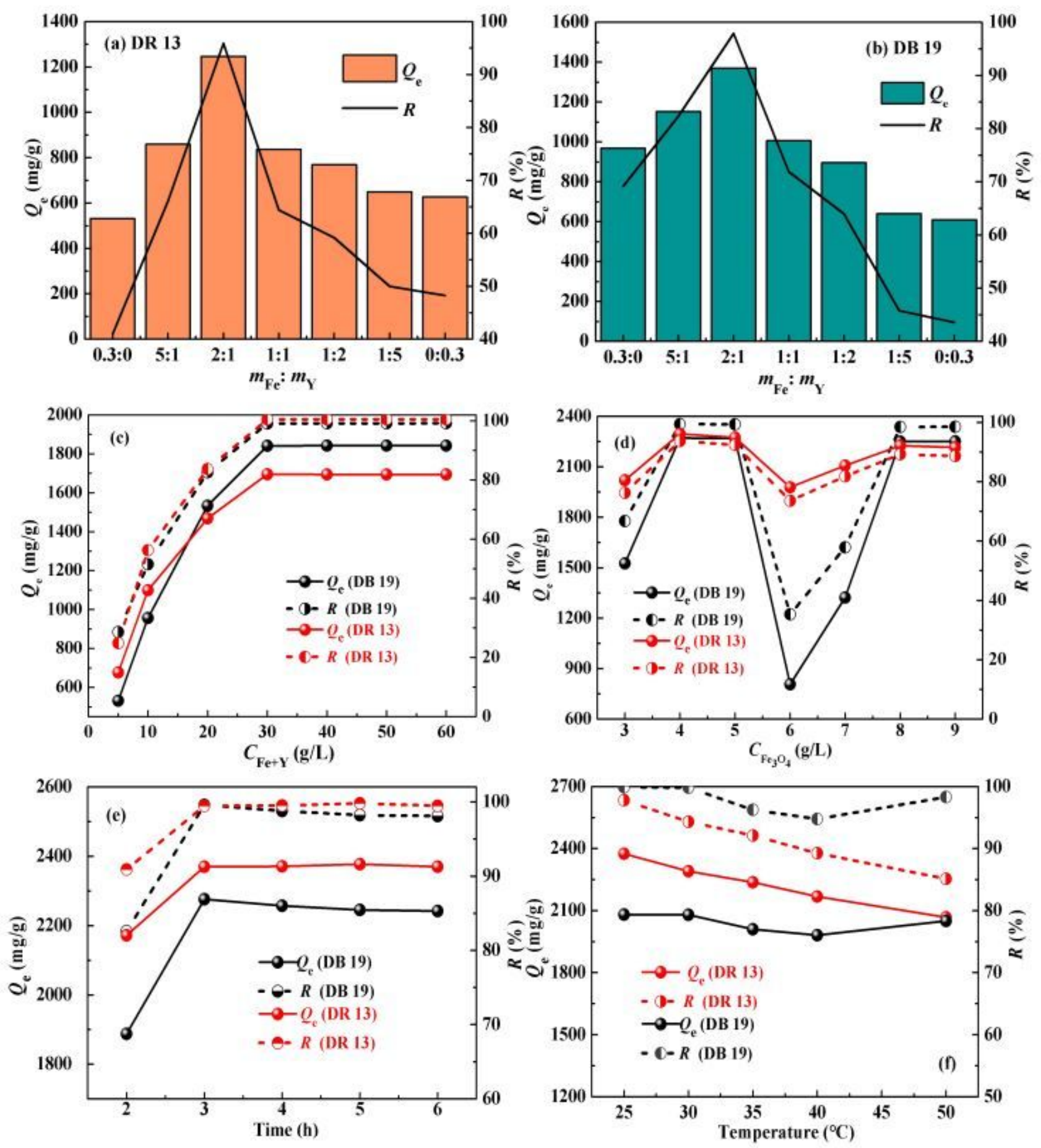

Figure 2

Effect of double ion mass ratio ( $a$ and b), total concentration of double ions (c), Fe304 concentration (d), curing time (e) and crosslinking reaction temperature ( $\mathrm{f}$ ) on the adsorption amounts and removal rates (2600 and $2800 \mathrm{mg} / \mathrm{L}$ of DR-13 and DB-19 dye concentration, 60 min of adsorption time) 

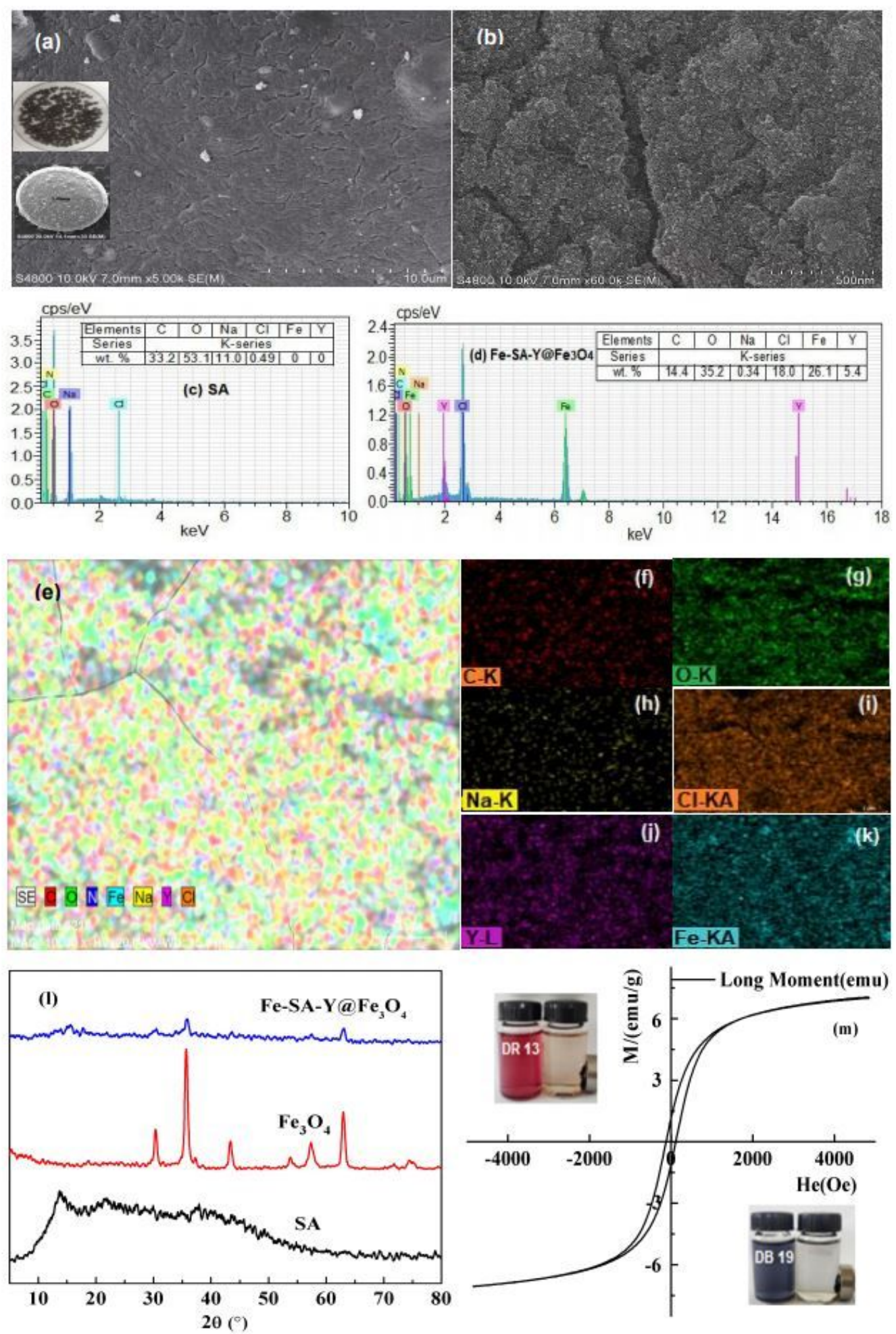

\section{Figure 3}

SEM images of Fe-SA-Y@Fe3O4 (a and b); EDS results (c and d) of SA and Fe-SA-Y@Fe3O4 and element distribution (e $\sim$ k) of the composite; (I) XRD patters of samples; $(\mathrm{m})$ Magnetic hysteresis loop of Fe-SAY@Fe304 

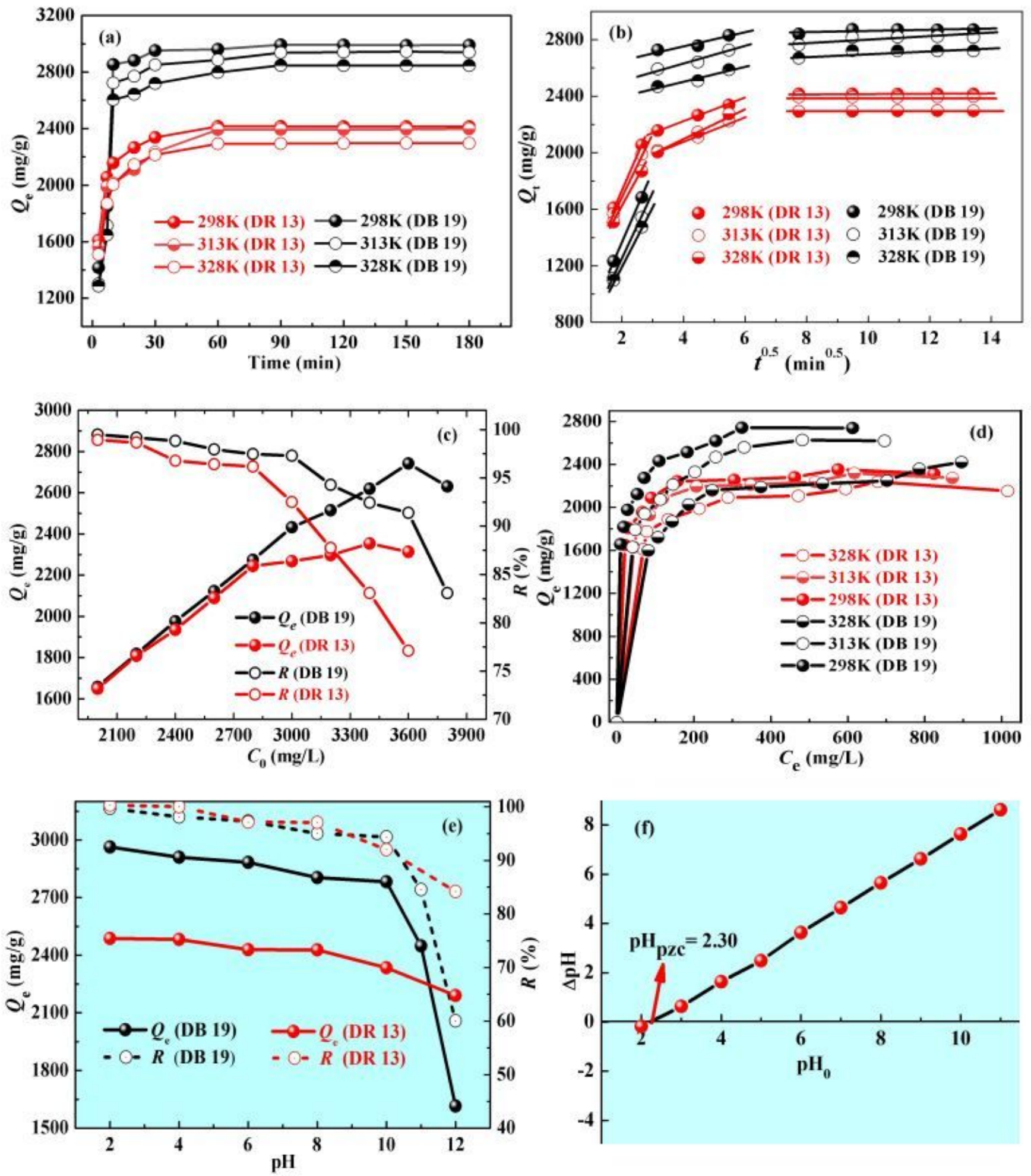

\section{Figure 4}

(a) Effect of contact time and temperature on dye adsorption; (b) The plots of Qt versus t0.5; (c) Effect of initial dye concentration on the adsorption; (d) Adsorption isotherms of two dyes on Fe-SA-Y@Fe304; (e) Effect of solution pH on dye adsorption; (f) Determination of the composite pHpzc 

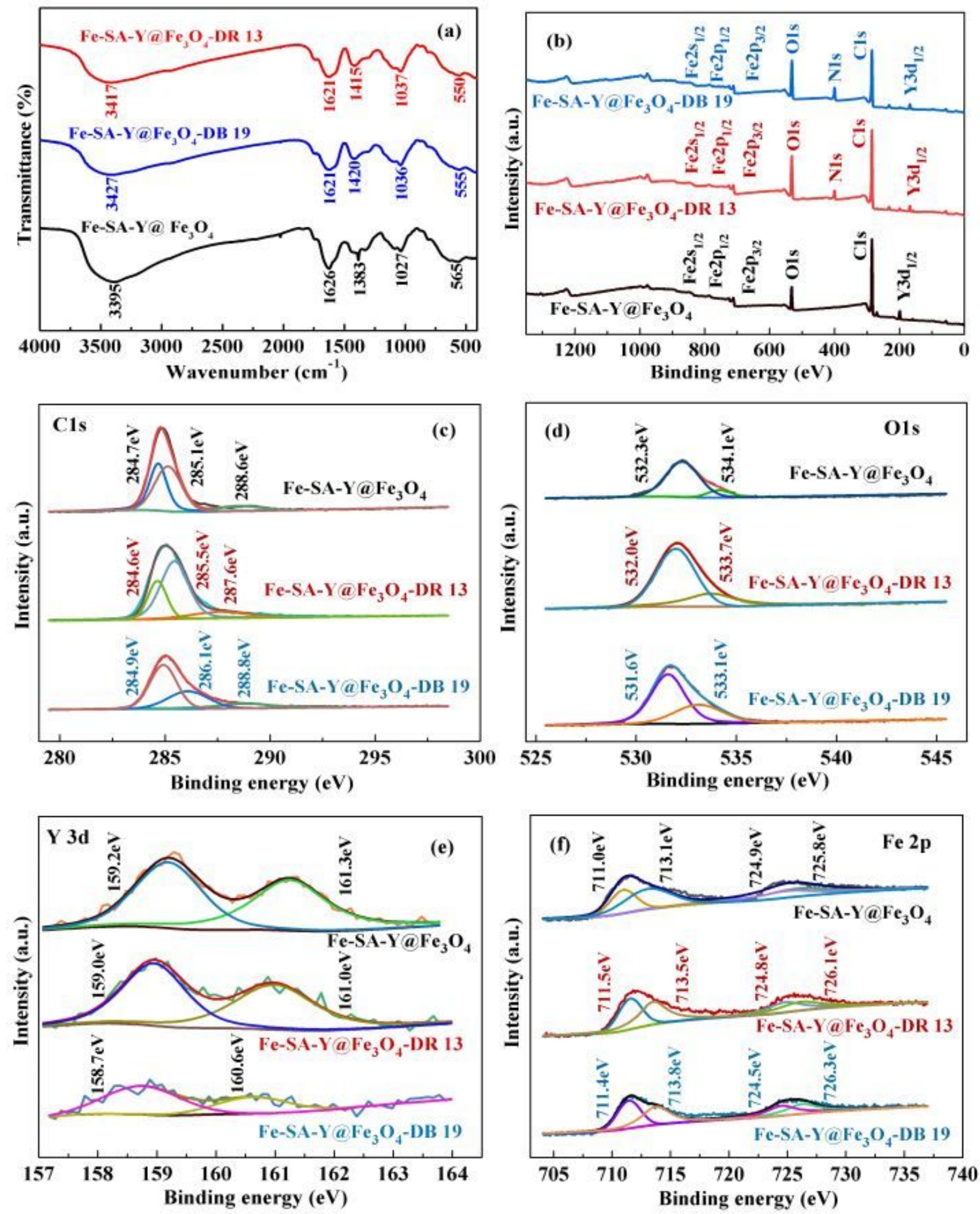

\section{Figure 5}

FTIR (a) and XPS spectra (b f) of the gel composite before and after dye adsorption 


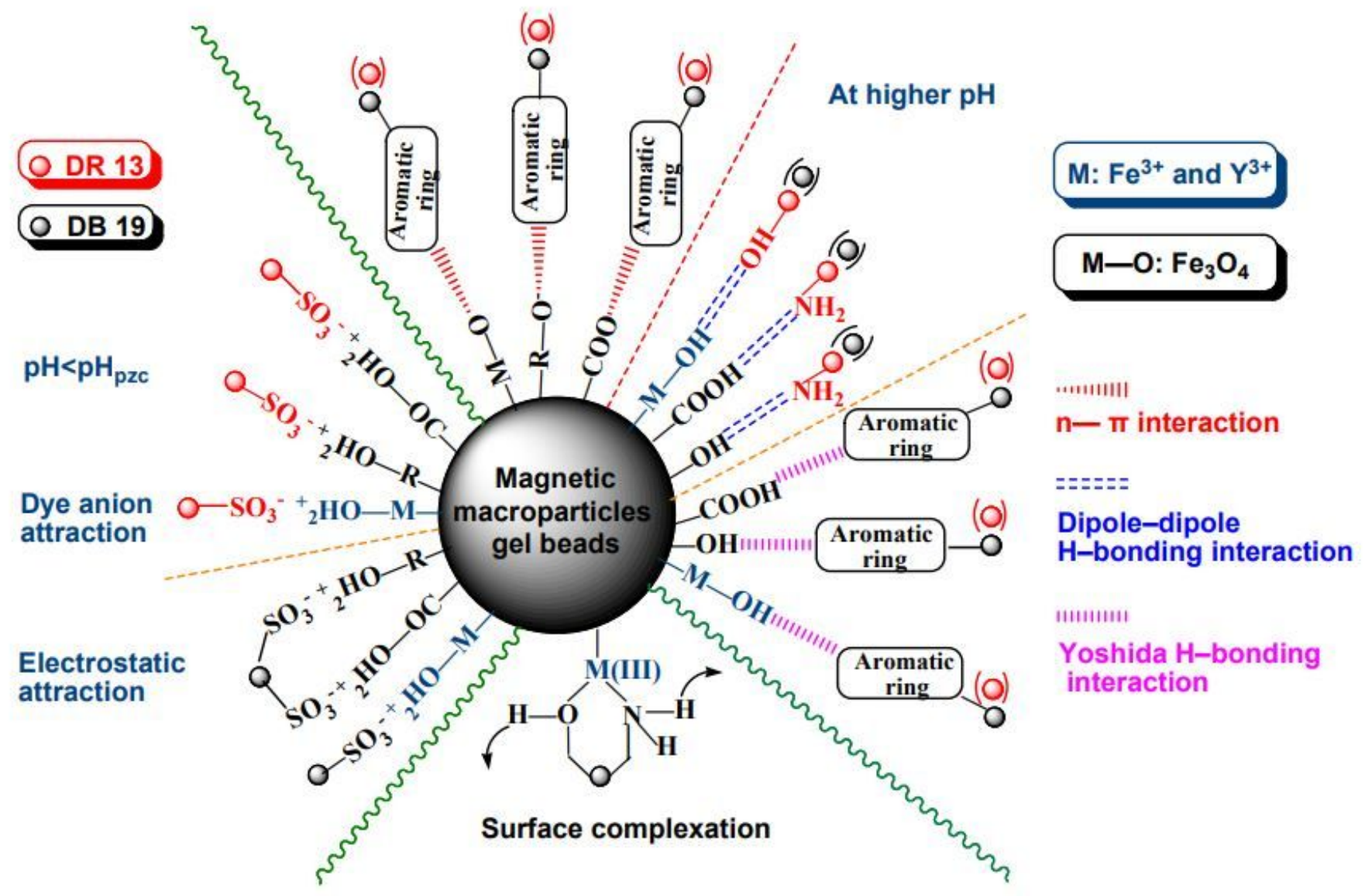

Figure 6

Suggested interaction between the magnetic gel composite and direct dyes 


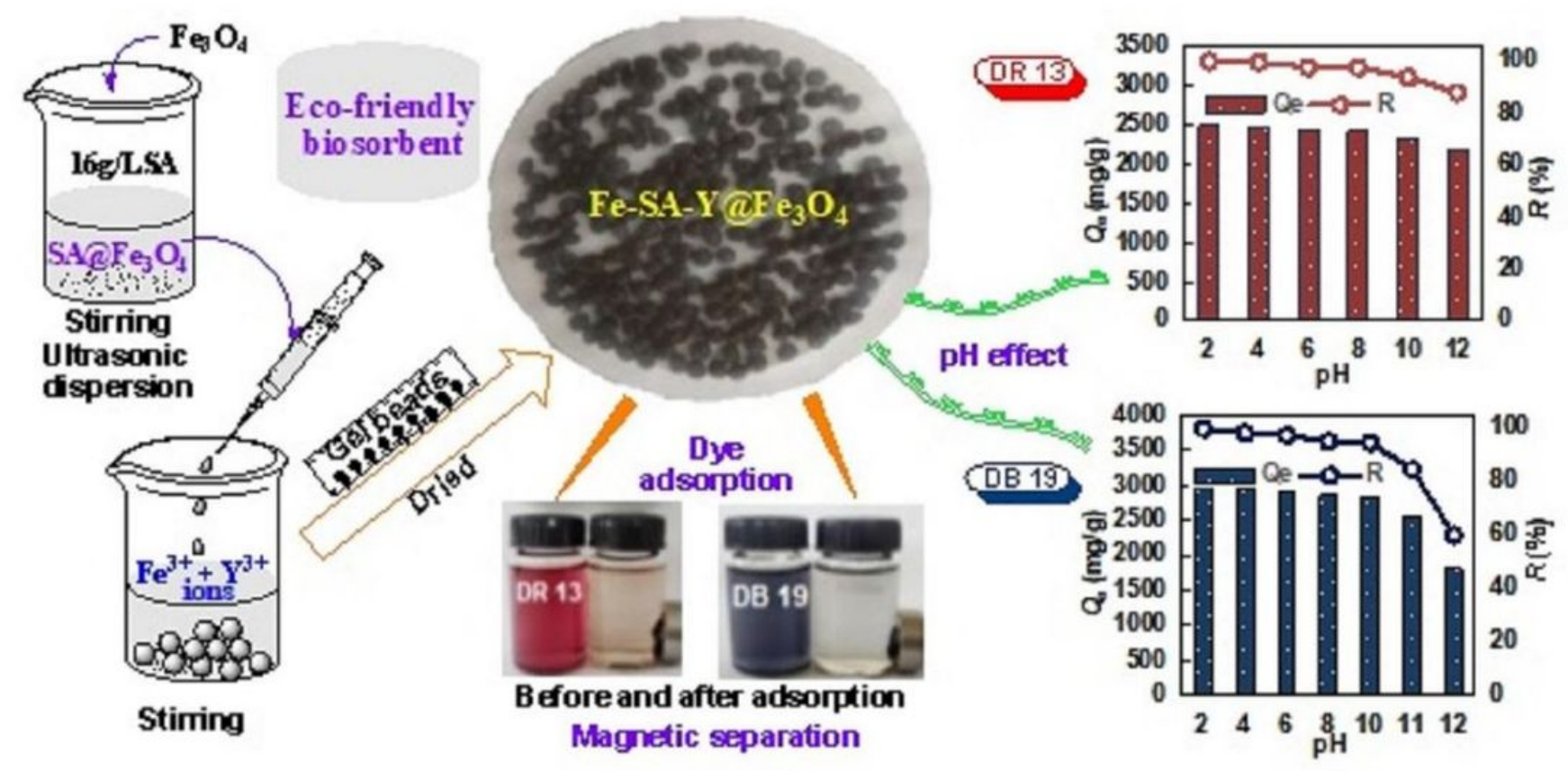

Figure 7

Sketch concerning advantages of Fe-SA-Y@Fe304 gel composite from raw materials, preparation to adsorption application

\section{Supplementary Files}

This is a list of supplementary files associated with this preprint. Click to download.

- Tables.pdf 